promises interesting results. At the present time, our experiments seem to sh ow that this juice will not emulsify fat. It acts more slowly upon albu minoids than the gastric juice, but very rapidly converts starchpaste. We hope to be able to separate the peculiar ferment more completely from the tissues, and then to study its reactions more thoroughly.

\section{DISLOCATION OF THE WRIST}

By FRANCIS G. HAMILTON, M.R.C.S.Eng., Assistant-Surgeon to the Central London Throat and Ear Hospital.

A CASE of dislocation of the wrist having been reported in the JOU RNAL for March $13^{\text {th }}$, by Mr. R. Anderson, induces me to send the following notes of a similar case. At the time when it occurred, $I$ was Senior House-Surgeon to the Royal Free Hospital, and the notes are reproduced from those then taken.

W. M., aged between 14 and $\mathbf{5}$, was brought to the Royal Free Hospital on August I2th, I876, at 6 P.M. The boy, when playing on a railway viaduct, had been chased by an official of the line, and had fallen from the viaduct, a distance of sixteen feet, striking his left side, and doubling his left wrist under him. On examination, a distinct semicircular projection was visible on the extensor aspect of the left fore-arm, about an inch and a half above the normal position of the wrist-joint, the convexity pointing upwards. There was another similar projection on the flexor aspect, in the normal pasition of the wrist-joint, with the concavity downwards. The fingers were semiflexed and flaccid. Both styloid processes could be plainly felt, immovable, and in the right position, as proved by comparing the two fore-arms, and by following down the subcutaneous lines of the ulna and radius. The convexity of the carpal articular surface and the concavity of the radio-ulnar could be distinctly felt, the hand itself being slightly drawn to the ulnar side. The diagnosis of dislocation of the carpus on to the extensor surface of the forearm was indubitable.

Reduction was effected without any difficulty by simple extension; it was sudden, and the deformity was at once removed, and did not return in any degree when extension was removed, and the movements of the joint could be then all elicited with but slight pain. The hand and forearm were placed on a straight splint, reaching from the elbow to the metacarpo-phalangeal joints on the flexor surface.

Twelve days later, the splint was removed, and the joint was found rather abnormally lax, and slightly swollen over the flexor tendons. The patient could supinate and pronate the forearm freely, and could also lift a light chair with the affected hand without pain. $\mathrm{He}$ said that, since the reduction, he had experienced no pain, and he had slept well.

A similar case of dislocation of the wrist backwards was reported by Mr. Alder Smith in the JOURNAL for June 24th, 1876 .

Mr. Holmes states, in his Surgery, that "dislocation of the wrist occurs almost always backwards", and that "dislocation in the other direetion (i.e., with the hand in front of the forearm) hardly ever occurs as a traumatic lesion". There is, however, a good illustration of a traumatic forward dislocation in Erichsen's Surgery, taken from a cast of a case of Mr. Cadge of Norwich.

Dr. Frank H. Hamilton, in his classical work on Fractures and Dislocations, relates a case of backward dislocation which he himself saw in an old man aged 75 . He also quotes another case, that of a lad about thirteen years old, who dislocated both wrists by being thrown from a horse, one wrist being dislocated backwards, and the other forwards.

The accident certainly but very seldom comes under the observation of surgeons; but Hamilton states, on the authority of Professor F. L. Parker of South Carolina, that there are thirty-three cases of wrist-dislocation on record, and of this number only ten were forwards, and the remaining twenty-three backwards; but he declares that only five of the backward, and two of the forward, dislocations are free from all objection. The cases reported by Mr. Alder Smith, Mr. R. Anderson, and myself agree in the following particulars. The patients were all aged about fifteen years, the diagnosis and the reductions were very easy, and the dislocations were all the result of great violence.

LOCH KATRINE WATER. - The monthly report of the quality of Loch Katrine water, prepared by Professor E. J. Mills of Anderson's College, has been issued. The results are returned in parts per 100,000: Total solid impurity, 2.90 ; organic carbon, o.158; organic nitrogen, o.or 7 ; ammonia, 0.000 ; nitric hydrogen, 0.008 ; total combined nitrogen, 0.025 ; chlorine, 0.63 ; hardness, 1.15. The water when sampled was light brown in colour, and contained little suspended matter.

\section{CLINICAL MEMORANDA.}

\section{NOTES ON THREE CASES OF PARACENTESIS THORACIS.}

THE first case I ever saw occurred when I was assistant-surgeon to the Newcastle Dispensary some years ago. A man, aged 48, had been suffering from chronic pleurisy of the right side, gradually followed by effusion of fluid therein. At a consultation of two physicians and myself, an operation was deemed necessary, as the only means left of affording the poor man any relief or chance of life. Accordingly, paracentesis thoracis was performed by introducing a fine trocar and camnula into the chest, between the fifth and sixth ribs, at the insertion of the serratus magnus muscle, and about one pint of straw-coloured fluid was carefully drawn off; that quantity being thought quite sufficient to remove at one time. After the lapse of a few days, the man died. At the post morkem examination, more than a gallon of fluid was found in the chest. The lung was compressed into a very small space against the vertebral column.

The second case happened in a strong and active woman aged 33, a person engaged behind the counter in a cocoa-room. She was attacked by acute pleurisy of the right side, followed by effusion of serum. Blisters, iodine (internally and externally), diuretics, and all sorts of drugs were used, but were of no avail. At the end of eight weeks, she was too ill to be moved out of bed. Assisted by my friend Mr. Angus, I removed, by means of Potain's aspirator, eighty ounces of clear straw-coloured fluid; this was all we could get through the needle. This patient recovered without a single bad symptom, except a rather protracted convalescence.

The third case was in a young and strong railway porter, aged 27, suffering from pleurisy, followed by effusion. I assisted my friend Dr. W. T. Wilson, of this town, to perform the operation by means of the aspirator, and we removed at one time one hundred and forty ounces of serum. The chest was not completely emptied; but a severe fit of coughing seizing the patient, we removed the needle for fear of injuring the lung tissue. This patient also completely recovered.

REMARKS. - Niemeyer recommends an early interference in such cases, whilst Tanner speaks very doubtfully of the operation at all. In the two last cases, much valuable time was lost by trying various medicaments, which were of no avail; and the result was to reduce the patients' strength, and render the convalescence more protracted. There is now little doubt that, as soon as the chest is detected to be full of fluid, an early paracentesis by means of the aspirator gives the patient the best and quickest chance of recovery. If carefully done, there is little danger attached to the operation. Preserving the patient's strength, shortening the period of confinement in bed, and preventing the permanent collapse of the lung, are the results which are to be ob. tained by an early and complete aspiration of the pleural cavity. ARTHUR T. WEAR, M.R.C.S.,

Honorary Surgeon to the Newcastle-on-Tyne Dispensary, etc.

\section{SURGICAL MEMORANDA.}

\section{REMOVAL OF A FOREIGN BODY FROM THE ORBITAL} CAVITY.

T. H. F., A SEANAN, aged 28, came to me a few days ago with the following history. Three weeks since, when with his ship off Greenock, he went ashore, being somewhat the worse for.drink at the time, to look for a shipmate. As he was gazing into the window of a factory, a workman thrust something into his eye. At first, he thought it had been merely his finger. Feeling pain in the eye, he applied to a medical man, who ordered him poultices and a wash of nitrate of silver. At times he felt a dull aching, which gradually became worse. A week later, on looking in the glass, he could see something in the eye, and pulled out a piece of pipe-stem broken in halves down the centre, which, from his description, would appear to be rather over one-third of an inch in length. He could see with the eye; but, still feeling pain, he was anxious to have something further done, and applied for advice at a hospital, but was told there was nothing the matter with the eye.

On examination, there was seen to be much chemosis, the conjunctiva-chiefly over the lower part of the globe-being swollen into thick projecting folds; and, on depressing the lower lid, a prominence of the membrane was observed, situated near the inner canthus, but covered by the lid when in situ. A hard body could be felt under this conjunctival swelling. The eye itself was forced somewhat backwards and upwards, but, as far as could be seen, was itself uninjured. A speculum was introduced to keep the lids well apart; and, on snipping through 